\title{
Modifiable risk factors of congenital malformations in bale zone hospitals, Southeast Ethiopia: an unmatched case- control study
}

\author{
Alemayehu Gonie Mekonnen ${ }^{1 *}$ (D), Alemu Girma Hordofa ${ }^{2}$, Tamiru Tesfaye Kitila ${ }^{3}$ and Adem Sav ${ }^{4}$
}

\begin{abstract}
Background: Congenital malformations are structural, functional, and metabolic defects that develop during the organogenesis period and present at birth or later in life. There has been little research on congenital malformations in Ethiopia, knowledge on the incidence of birth defects at birth is unknown and the etiologies of the anomalies are limited. This study, therefore, aimed to assess the modifiable risks of congenital anomalies among women in Bale zone hospitals, Ethiopia.
\end{abstract}

Methods: An unmatched case-control study was conducted from February 2018 to January 2019 in the Bale zone; namely Goba referral hospital, Robe, Ginnir and Dolomena hospitals. A total of 409 women were selected. Mothers who gave birth with any type of congenital malformation were assigned as cases and those who gave live births without any congenital abnormalities were assigned as controls. Controls were selected by the lottery method from the labor ward. For each case, two consecutive controls were included. Data were entered into Epi-data 3.1 and exported into Statistical Package for the Social Sciences (SPSS) version 21 for analysis. Logistic regression was conducted to analyze the data.

Results: Alarmingly, women who had been exposed to pesticides during the current pregnancy were two times more prone to give congenital malformed infants than their counterparts ( $A O R=3.19 ; 95 \% \mathrm{Cl}=1.31,10.96$ ). Additionally, those women who chewed khat during the periconceptional period were two times more likely to have congenital malformed infants as compared to women who did not engage in this activity (AOR $=2.40 ; 95 \%$ $\mathrm{Cl}=1.11,5.19)$.

Conclusions: Urgent attention needs to be given by public health professionals and services to khat chewing and maternal exposure to pesticides during pregnancy to reduce the risk of congenital malformations.

Keywords: Birth defects, Congenital malformation, Infants, Ethiopia

\section{Background}

Congenital malformations $(\mathrm{CM})$ are structural, functional, and metabolic defects that develop during the

\footnotetext{
* Correspondence: alemayehugonie19@gmail.com

'Department of Nursing, College of Health Sciences, Debre Berhan University, Po. Box, 445 Debre Berhan, Ethiopia

Full list of author information is available at the end of the article
}

organogenesis period and present at birth or detected later in life [1]. These malformations are present in 3\% of all newborns and responsible for nearly $7 \%$ of neonatal deaths worldwide [2]. Congenital malformations can be caused by genetic, chromosomal, environmental, multifactorial effects, and micronutrient deficiencies or unknown etiological agents $[3,4]$. A strong association

(C) The Author(s). 2020 Open Access This article is licensed under a Creative Commons Attribution 4.0 International License, which permits use, sharing, adaptation, distribution and reproduction in any medium or format, as long as you give appropriate credit to the original author(s) and the source, provide a link to the Creative Commons licence, and indicate if changes were made. The images or other third party material in this article are included in the article's Creative Commons licence, unless indicated otherwise in a credit line to the material. If material is not included in the article's Creative Commons licence and your intended use is not permitted by statutory regulation or exceeds the permitted use, you will need to obtain permission directly from the copyright holder. To view a copy of this licence, visit http://creativecommons.org/licenses/by/4.0/. The Creative Commons Public Domain Dedication waiver (http://creativecommons.org/publicdomain/zero/1.0/) applies to the data made available in this article, unless otherwise stated in a credit line to the data. 
has been reported between maternal pre-pregnancy obesity and certain birth defects [5,6]. Although genetic factors account for $20 \%$ of the risks, the majority of birth-defects are environmental factors [1, 3]. For example, environmental teratogens (exposure to medicines, certain environmental chemicals, alcohol intake) have been reported to have an adverse and disruptive effect on the embryo or the fetus [7-9]. Environmental teratogen has mechanical effects on the vascular and the amnion disruptions by increasing the risk of malformation pathology $[6,10]$. Maternal infections with syphilis and rubella are also stated as the risk of birth-defects in low and middle-income countries [11].

The incidence of congenital malformation varies widely from country to country [2] and from region to region, with a range of 1.73 to $6.3 \%$ [12-14]. For example, it was reported to be $1.7 \%$ in Brazil [15], 2.22\% in Eastern India [16], 3.63\% in Iraq [17], 6.3\% in Nigeria $6.3 \%$ [14]. One such country with high rates of congenital malformation is Ethiopia. In central and north-west Ethiopia, the proportion of congenital anomaly was 199 per 10,000 children who visited the hospitals [18]. This is not surprising as evidence indicated that the highest numbers of birth defects occurred in low and middleincome countries where environmental teratogenic risk factors were more problematic as compared to highincome countries $[2,19]$. Indeed, there was evidence that suggested childbearing-age women in developing countries like Ethiopia are exposed to potential teratogenic risks like infectious agents and environmental chemical compounds $[20,21]$. For example, in a study conducted in Addis Ababa showed that women were exposed to high concentrations of metals, nitrates, coliform, and other pathogens which might cause birth-defects [22].

There was widespread recognition that the prevention of congenital malformations during pregnancy requires risk identification [11]. Indeed, the identification of modifiable risk factors of birth defects provide an opportunity for primary prevention which include prevention of sexually transmitted infections, promoting healthy dietary habits and fortification of foods with folic acid, and preventing maternal infections during the periconceptional period (1 month before conception and 1 month after conception) [23]. However, in order to identify, such modifiable risk factors that have been associated with a congenital malformation, health care providers need evidence-based information. More specifically, they need to know which modifiable risk factors can lead to congenital malformation.

Knowledge about congenital anomalies is useful to identify clues to risk factors of conditions, for health services planning and evaluating antenatal screening in populations with high risk [2,17]. Based on this premise, many studies have investigated the risk factors of congenital anomalies [21, 24, 25]. Although these studies have increased our awareness of the link between modifiable risk factors and congenital malformations, some have significant limitations such as study design, lack of proper sample size, and lack of control group [11, 16]. In Ethiopia, there is a scarcity of research on congenital malformations. There is currently very limited knowledge on the incidence of CMs at birth and the etiologies of the anomalies are limited. Besides, the incidence of $\mathrm{CM}$ and the modifiable risk factors could be significantly different in Ethiopia than high-income countries (where most research has occurred), because of unique cultural and societal issues in this country. Without such knowledge, healthcare professionals will have very limited ability to identify Ethiopian women who are at risk of developing CMs and they have been limited in implementing effective treatment programs. Hence, the first step in preventing and treating the incidence of CMs at birth in Ethiopia could be understanding the modifiable risk factors that are likely to lead to this health issue. This study, therefore, aimed to assess the modifiable risks of congenital malformations in Bale zone hospitals, Ethiopia, a country where there are high rates of CMs.

\section{Methods}

\section{Study area and period}

The study was conducted from February 2018 to January 2019 in Bale zone hospitals; namely Goba referral hospital, Robe, Ginnir and Dello-Menna hospitals in Ethiopia. The Bale zone is located in the southeastern part of Ethiopia. Robe, the zone city, is located $435 \mathrm{~km}$ far from the capital city of Ethiopia; Addis Ababa. Based on the 2007 census conducted by the Central Statistical Agency, this Zone has a total population of 1,402,492 of which $26.20 \%$ are urban inhabitants and $3.18 \%$ are pastoralists.

The above-mentioned hospitals provide almost all types of obstetric care and babies are routinely screened for congenital abnormalities before discharge from the maternity unit. In the study hospitals, the exact number of birth defects was unknown, but on average, 6 congenital anomalies have been screened in each hospital per month (Bale zone health office report 2018).

\section{Study design}

An unmatched case-control study design was employed to achieve the objectives.

\section{Study population}

All infants born from February 2018 to January 2019 were the total study population. Mothers who gave birth with any type of congenital malformation were assigned as cases and mothers who gave live birth without birth defects were assigned as controls. Minor defects were 
excluded from the study because of the difficulties in ascertaining such defects. If multiple CMs were diagnosed, the primary major birth-defect was taken (spinal bifida with clubfoot, spinal bifida was taken).

\section{Sample size determination}

The sample size was calculated using Fleiss formula from the Open-Epi software package with considering the following unmatched case-control study parameters (proportion difference approach) [26]: The proportion of the desired confidence level $=95 \%$. The power (chance of detecting $)=80 \%$. The least extreme odds ratio to be detected (the strength of relationship expected to be found among cases \& controls) $=2$. The ratio of the case to control was 1:2. Hypothetical percentage of exposure among controls by considering the most common congenital malformations (cleft lip) $=18 \%$ [3]. Using these values, the percent of expected exposure among cases was $30.5 \%$. With the above assumptions and by adding a non-response rate of 5\%, the final sample size was 423 (141 cases and 282 controls).

\section{Sampling procedure}

All mothers who delivered infants with congenital anomalies within the study period were invited to participate in the study. Congenital malformation was diagnosed by Obstetricians at the time of delivery. Mothers who had delivered infants with no congenital anomalies were also recruited as a control group. Controls were selected from the same ward as the same day of case incidence. The required numbers of controls were selected by the lottery method from the labor ward. For each case, two consecutive controls were included.

\section{Data collection}

A structured and pre-tested questionnaire was employed to collect data (Additional file 1). The questionnaire was prepared first in English from published articles and then translated into Amharic and Afan Oromo (local languages) by expertise, and its reliability and validity were confirmed with $5 \%$ of the sample. Data collectors and supervisors were trained by principal investigators before the data collection. Data on the following variables were collected in the questionnaire: sociodemographic characteristics, obstetric characteristics (birth interval, number of children, antenatal care follow up, use of contraceptives), maternal medical histories and toxic or environment exposure status.

\section{Operational definition}

Cases

Are those mothers who gave birth with any type of congenital malformation. Controls: are those mothers who gave live birth without any identified congenital malformation.

\section{Congenital malformations}

are defined as structural, functional, and metabolic defects that develop during the organogenesis period and detected at birth. The diagnosis of congenital anomalies was confirmed through clinical examination during childbirth. In this study, the terms; birth defects, congenital abnormalities, and congenital malformations are synonymous, and we used the terms interchangeably throughout the document.

\section{Data processing and analysis}

Data were checked for completeness and inconsistencies. Epi-data version 3.1 was used for data entry and data were exported into Statistical Package for the Social Sciences (SPSS) version 21. Descriptive statistics were computed. To identify the factors, which were significantly associated with the risk of congenital malformation, multiple logistic regression was performed. Independent variables that had a significant association in the bivariate analysis were entered into the multivariable analysis. In the final model, a significant association was declared at a $p<0.05$. The results were presented in text and tables with adjusted odds ratio (AOR) and the corresponding $95 \%$ confidence interval.

\section{Ethical consideration}

Ethical approval was obtained from a research review committee of Madawalabu University. Letters were secured from the Bale zone Health Bureau and respective hospitals. Written informed consent was obtained from each study participant. All information obtained from each study participant was kept confidential throughout the study, and the name of the participant was replaced by code. Withdrawal from the study at any point if they wished was assured.

\section{Results}

\section{Maternal socio-demographic characteristics}

A total of four hundred nine women (136 cases and 273 controls) were successfully interviewed via questionnaires, giving a response rate of $96.7 \%$ for both cases and controls. About $35 \%$ (34.8\%) of controls and nearly one-third of cases (29.4) were in the age group of 21-25 years. The largest proportions of respondents, $96.3 \%$ of cases and $97.1 \%$ of controls were married. Around $64 \%$ of women among cases and $60.8 \%$ of women among controls were Muslim. The majority of women $(65.4 \%$ of cases versus $55.0 \%$ of controls) were housewives. Concerning the educational level of the respondents, 37.5\% of cases and $27.8 \%$ of controls did not attend formal education and a small proportion of participants 
Table 1 Sociodemographic characteristics of mothers in Bale zone hospitals, Ethiopia, January, 2019

\begin{tabular}{|c|c|c|c|}
\hline Characteristics & Categories & Cases n (\%) & Controls n (\%) \\
\hline \multirow[t]{5}{*}{ Age of respondents (in years) } & $\leq 20$ & $16(11.8)$ & $31(11.3)$ \\
\hline & $21-25$ & $40(29.4)$ & $95(34.8)$ \\
\hline & $26-30$ & $37(27.2)$ & $83(30.4)$ \\
\hline & $31-35$ & $25(18.4)$ & $41(15.1)$ \\
\hline & $\geq 36$ & $18(13.2)$ & $23(8.4)$ \\
\hline \multirow[t]{2}{*}{ Marital status of respondents } & Married & $131(96.3)$ & $265(97.1)$ \\
\hline & Single/separated & $5(3.7)$ & $8(2.9)$ \\
\hline \multirow[t]{4}{*}{ Religion of respondents } & Muslim & $87(64.0)$ & $166(60.8)$ \\
\hline & Orthodox & $42(30.9)$ & $83(30.4)$ \\
\hline & Protestant & $5(3.7)$ & $17(6.2)$ \\
\hline & Catholic & $2(1.4)$ & $7(1.6)$ \\
\hline \multirow[t]{4}{*}{ The educational level of respondents } & Illiterate & $51(37.5)$ & $76(27.8)$ \\
\hline & Primary education & $43(31.6)$ & $68(24.9)$ \\
\hline & Secondary education & $23(17.0)$ & $73(26.8)$ \\
\hline & College education & 19 (13.9) & $56(20.5)$ \\
\hline \multirow[t]{5}{*}{ Occupation of respondents } & Housewife & $89(65.4)$ & $145(55.0)$ \\
\hline & Employed & $18(13.2)$ & $45(16.5)$ \\
\hline & Farmer & $15(11.1)$ & $41(15.1)$ \\
\hline & Marchant & $11(8.1)$ & $38(13.9)$ \\
\hline & Others (daily laborer \& student) & $3(2.2)$ & $4(1.5)$ \\
\hline \multirow[t]{2}{*}{ Residence of respondents } & Urban & $71(52.2)$ & $167(61.2)$ \\
\hline & Rural & $65(47.8)$ & $106(38.8$ \\
\hline
\end{tabular}

completed college education $(13.9 \%$ of cases versus $20.5 \%$ of controls). Almost half $(52.2 \%)$ of cases lived in an urban area (Table 1).

\section{Obstetrics characteristics of respondents}

Out of the total study participants, nearly half of both controls (48.6\%) and cases (44.1\%) were multigravidas. Twenty-one percent (21.6\%) of cases and $18.4 \%$ of controls reported a history of abortion/pregnancy loss before 28 weeks of gestation. A higher percentage of cases (4.1\%) and $2.3 \%$ of controls reported that they had a family history of anomalies. Around $42 \%$ of cases and a half $(49.6 \%)$ of controls utilized contraceptives before the current pregnancy (Table 2).

\section{Maternal medical histories}

There was no major difference between maternal previous medical histories (pregnancy-induced hypertension, diabetes, and hyperthyroid disorder) and having congenital malformed infants. Nearly equal proportion of respondents, $6.6 \%$ of cases and $7.3 \%$ of controls reported a history of pregnancy-induced hypertension. A few percent (2.2\%) of cases had been diagnosed with the hyperthyroid disorder before the current birth. Similarly, less than $2 \%$ of the cases and 2.2\% of controls reported a history of diabetes before the current birth. Regarding the prior family history of anomalies, $7.4 \%$ of the cases and $2.5 \%$ of controls reported a family history of anomalies. About $12.9 \%$ of cases and $9.1 \%$ of controls have been diagnosed with anemia during current pregnancy (Table 3).

\section{Toxic or environment exposure status}

As can be seen from Table 4, a slightly higher proportion of women who had congenital malformed infants had been exposed to toxic environments. Thirteen percent (13.2\%) of cases and $4.2 \%$ control mothers have been exposed to pesticides during pregnancy. Twenty-one percent (21.1\%) of cases and $8.8 \%$ of control mothers reported that they were chewing $k h a t^{1}$ during the periconceptional period (1 month before conception and 1 month after conception). The reported consumption of alcohol during the current pregnancy was 11.2 and $4.8 \%$ for case and control women, respectively. Around half (49.3\%) of cases and $61.5 \%$ of control mothers reported that they had a separate cooking kitchen.

\footnotetext{
${ }^{1}$ Khat is a plant and its leaves and stem are chewed by people to elevate mood. It is mostly practiced in East Africa and the Arabian countries.
} 
Table 2 Obstetrics characteristics of mothers in Bale zone hospitals, Ethiopia, January 2019

\begin{tabular}{|c|c|c|c|}
\hline Obstetrics Characteristics & Categories & Cases & Controls \\
\hline \multirow[t]{3}{*}{ Gravida } & Primigravida & $39(28.7)$ & $66(24.2)$ \\
\hline & Multigravida & $61(44.8)$ & $132(48.3)$ \\
\hline & Grand multigravida & $36(26.5)$ & $75(27.5)$ \\
\hline \multirow[t]{3}{*}{ Gestational age } & $<28$ weeks & $19(14.0)$ & 0 \\
\hline & $\geq 28-37$ weeks & $70(51.5)$ & $12(4.4)$ \\
\hline & $\geq 37$ weeks & $47(34.5)$ & 261 (95.6) \\
\hline \multirow[t]{2}{*}{ Number of infants delivered } & Single & $111(81.6)$ & $262(95.9)$ \\
\hline & Twin and above & $25(18.4)$ & $11(4.1)$ \\
\hline \multirow[t]{3}{*}{ Fetal sex } & Female & $65(48.4)$ & $141(51.6)$ \\
\hline & Male & $64(47.1)$ & $132(48.4)$ \\
\hline & Undefined & $7(5.5)$ & 0 \\
\hline \multirow[t]{2}{*}{ Did you have previous pregnancy neonatal death? $(n=304)$} & Yes & $5(5.2)$ & $6(2.9)$ \\
\hline & No & $92(94.8)$ & $201(97.1)$ \\
\hline \multirow[t]{2}{*}{ Did you have an abortion history/pregnancy loss before 28 weeks? $(n=304)$} & Yes & $20(21.6)$ & $37(18.4)$ \\
\hline & No & $77(79.4)$ & $169(81.6)$ \\
\hline \multirow[t]{2}{*}{ Did you have a family history of anomalies? $(n=304)$} & Yes & $4(4.1)$ & $6(2.3)$ \\
\hline & No & $93(95.9)$ & $201(97.7)$ \\
\hline \multirow[t]{2}{*}{ Did you use contraceptives before the current pregnancy? } & Yes & $40(41.3)$ & $102(49.6)$ \\
\hline & No & $57(58.7)$ & $105(50.4)$ \\
\hline
\end{tabular}

\section{The type of congenital malformation}

As shown in Fig. 1, various types of congenital malformations were diagnosed during the study period. Out of 136 congenital malformations, $42(31.0 \%)$ of them were anencephaly and $27(19.8 \%)$ were spinal bifida. Of the anomalies, the proportion of gastroschaisis, umbilical hernia, and meningoencephalocele were $2.2 \%$ (Fig. 1).

\section{Risk factors associated with congenital malformation}

The bivariate logistic regression analyses were performed between independent variables and congenital malformation. The analyses revealed that women's occupation, residence, number of infants, have been exposed to pesticides during pregnancy, have been drinking alcohol during pregnancy, and have been chewing Khat during

Table 3 Medical histories of mothers in Bale zone hospitals, Ethiopia, January 2019

\begin{tabular}{|c|c|c|c|}
\hline Maternal medical histories & Categories & Cases n (\%) & Controls n (\%) \\
\hline \multirow[t]{3}{*}{ Did you have a history of pregnancy-induced hypertension? } & Yes & $9(6.6)$ & $20(7.3)$ \\
\hline & No & $108(79.4)$ & $221(81.0)$ \\
\hline & Do not know & $19(14.0)$ & $32(11.7)$ \\
\hline \multirow[t]{3}{*}{ Did you have a family history of anomalies? } & Yes & $10(7.4)$ & $7(2.5)$ \\
\hline & No & $104(76.5)$ & $227(83.2)$ \\
\hline & Do not know & $22(16.1)$ & $39(14.3)$ \\
\hline \multirow[t]{3}{*}{ Did you have been diagnosed with a hyperthyroid disorder? } & Yes & $3(2.2 \%)$ & $8(2.9)$ \\
\hline & No & $122(89.7)$ & $237(86.8)$ \\
\hline & Do not know & $11(8.1)$ & $28(10.3)$ \\
\hline \multirow[t]{3}{*}{ Did you have a history of diabetes? } & Yes & $2(1.5)$ & $6(2.2)$ \\
\hline & No & $98(72.0)$ & $211(77.3)$ \\
\hline & Do not know & $36(26.5)$ & $56(20.5)$ \\
\hline \multirow[t]{3}{*}{ Did you have been diagnosed with anemia? } & Yes & $17(12.5)$ & $24(8.8)$ \\
\hline & No & $98(72.0)$ & $210(76.9)$ \\
\hline & Do not know & $21(15.5)$ & 39 (14.3) \\
\hline
\end{tabular}


Table 4 Environment exposure status of mothers in Bale zone hospitals, Ethiopia, January 2019

\begin{tabular}{|c|c|c|c|}
\hline Toxic or environment exposure status & Category & $\begin{array}{l}\text { Cases N } \\
(\%)\end{array}$ & $\begin{array}{l}\text { Controls N } \\
(\%)\end{array}$ \\
\hline \multirow[t]{2}{*}{ Have you been exposed to pesticides during pregnancy? } & Yes & $18(13.2)$ & $11(4.1)$ \\
\hline & No & $118(86.8)$ & $262(95.9)$ \\
\hline \multirow[t]{2}{*}{ Did you smoke a cigarette during the current pregnancy? } & Yes & $4(2.9)$ & $4(1.5)$ \\
\hline & No & $132(97.1)$ & $269(98.5)$ \\
\hline \multirow[t]{2}{*}{ Did you ever chew khat during the peri-conceptional period? } & Yes & $28(21.1)$ & $24(8.8)$ \\
\hline & No & $108(79.4)$ & $249(91.2)$ \\
\hline \multirow[t]{2}{*}{ Have you consumed/drank alcohol during the current pregnancy? } & Yes & $16(11.2)$ & $13(4.8)$ \\
\hline & No & $120(88.8)$ & $260(95.2)$ \\
\hline \multirow{2}{*}{$\begin{array}{l}\text { Have you been exposed to organic solvents (chemicals used in industries or installations e.g. benzene, methanol) } \\
\text { during the pregnancy? }\end{array}$} & Yes & $6(4.4)$ & $6(2.2)$ \\
\hline & No & $130(95.6)$ & $267(97.8)$ \\
\hline \multirow[t]{2}{*}{ Have you been exposed to heavy metals (mercury, lead, arsenic, aluminum) during the current pregnancy? } & Yes & $3(2.2)$ & $5(1.9)$ \\
\hline & No & $133(97.8)$ & $268(98.1)$ \\
\hline \multirow[t]{2}{*}{ Have you been undergone $X$-ray/radiation therapy during pregnancy? } & Yes & $2(1.4)$ & $3(1.1)$ \\
\hline & No & $134(97.6)$ & $270(98.9)$ \\
\hline \multirow[t]{2}{*}{ Did you use a separate cooking kitchen? } & Yes & $65(47.8)$ & $153(56.0)$ \\
\hline & No & $71(52.2)$ & $120(44.0)$ \\
\hline \multirow[t]{2}{*}{ Was there any ventilation during heating/cooking? } & Yes & $67(49.3)$ & $168(61.5)$ \\
\hline & No & $69(50.9)$ & $105(38.5)$ \\
\hline \multirow[t]{2}{*}{ Have you used a coal stove for heating? } & Yes & $98(72.1$ & $213(78.0)$ \\
\hline & No & $38(27.9$ & $60(22.0)$ \\
\hline
\end{tabular}

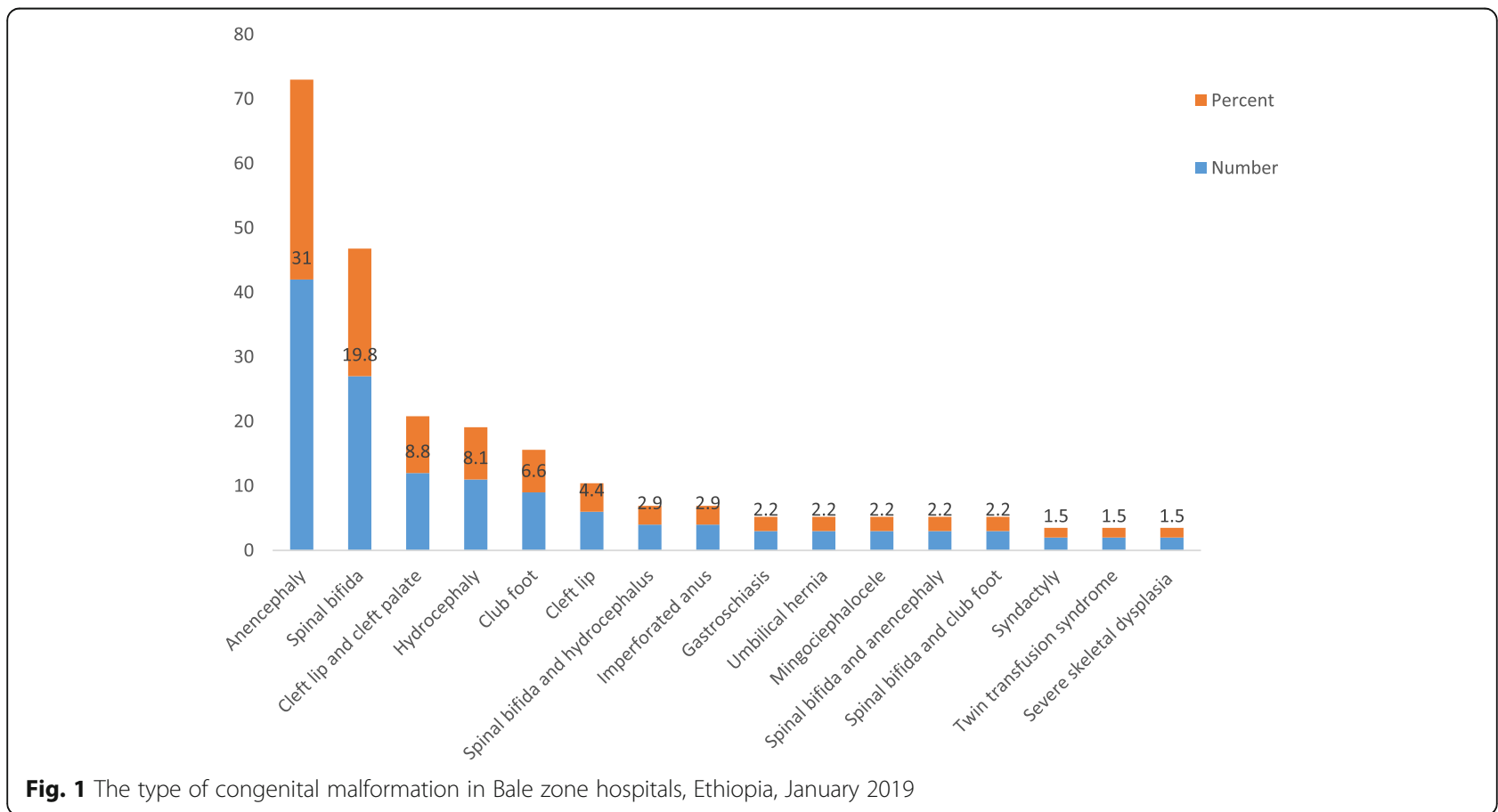


the periconceptional period were statistically significant with a congenital malformation in the bivariate model. Those variables which had a significant association with a congenital malformation in the bivariate model were entered into multiple logistic regression analyses. The results of the analysis showed that women who have been exposed to pesticides during the current pregnancy were three times more prone to give congenital malformed infants than their counterparts (AOR $=3.19 ; 95 \%$ $\mathrm{CI}=1.31,10.96)$. Likewise, the likelihood of giving congenital malformed infants was significantly higher among women who chewed khat during the periconceptional period. In fact, women who chewed khat during their periconceptional period were two times more likely to have congenital malformed infants as compared to women who did not engage in this activity $(\mathrm{AOR}=2.40$; $95 \% \mathrm{CI}=1.11,5.19)($ Table 5).

\section{Discussions}

This is one of the few studies that shed light on the understanding of the modifiable risk factors of congenital malformations in Southeast Ethiopia, thereby helping health professionals and health services to tailor suitable treatment and prevention programs in this context. In an era of increasing pressures on health systems worldwide [27], our study brings us one step close to ensuring that by understanding the modifiable risk factors for $\mathrm{CM}$, and how health services are delivered efficiently and optimally. In this study, maternal obstetric and medical histories did not have significant associations with delivering congenital malformed infants. This could be because obstetric and medical history variables did not affect the formation of congenital malformation. However, our result showed that women who have been exposed to pesticides during pregnancy and who chewed khat during their periconceptional period were at higher risk to deliver congenital malformed infants. Alarmingly, we found that women who had been exposed to pesticides during the current pregnancy were two times more prone to give congenital malformed infants than their counterparts. This adds to the overwhelming body of evidence on the negative impact of pesticide exposure on pregnancy outcomes worldwide. For example, a study conducted in Southern France revealed that being exposed to pesticides during pregnancy was associated with the risk of fetal congenital malformation [28]. Bianchi $\mathrm{F}$ et al. also reported that the association between birth defects and being exposed to textile dye [25]. In agreement with our results, the authors reported that being exposed to chemicals during pregnancy played a significant role in having an infant with a major birth defect [13, 29].

Our study adds to this body of evidence by suggesting that exposure to toxic chemicals during pregnancy has a detrimental impact on pregnant women in counties where there is very little or limited evidence (e.g., Ethiopia). With the rise in pollution levels in major cities worldwide, we are likely going to face even greater challenges regarding this issue. Clearly, it appears that environmental chemicals are harmful to fetal development and this is a key public health challenge that health professionals are facing worldwide. However, health professionals alone may have a limited ability to develop interventions or find solutions to prevent exposure to toxic chemicals during pregnancy. Instead, more coordinated efforts by all those involved in prenatal care and early pregnancy including broad level interventions by governments might be required to prevent toxic exposure during pregnancy.

Table 5 The analysis of risk factors associated with a congenital malformation in Bale zone hospitals, Ethiopia, January 2019

\begin{tabular}{|c|c|c|c|c|c|c|c|}
\hline Characteristics & Category & Case & Control & COR $(95 \% \mathrm{Cl})$ & $p$-value & AOR (95\% Cl) & $p$-value \\
\hline \multirow[t]{4}{*}{ Occupation of women } & Housewife & $89(65.4)$ & $145(55.0)$ & $2.12(1.76,7.31)$ & 0.031 & $2.79(0.28,4.47)$ & 0.171 \\
\hline & Employed & $18(13.2)$ & $45(16.5)$ & $1.38(0.49,8.32)$ & 0.210 & $1.03(0.91,7.90)$ & 0.125 \\
\hline & Farmer & $15(11.1)$ & $41(15.1)$ & $1.26(0.44,3.01)$ & 0.545 & $1.55(0.88,15.54)$ & 0.725 \\
\hline & Marchant & $11(8.1)$ & $38(13.9)$ & 1 & & 1 & \\
\hline \multirow[t]{2}{*}{ Residence of women } & Urban & $71(52.2)$ & $167(61.2)$ & $0.69(0.54,1.81)$ & 0.011 & $0.56(0.43,5.83)$ & 0.160 \\
\hline & Rural & $65(47.8)$ & $106(38.8$ & 1 & & 1 & \\
\hline \multirow[t]{2}{*}{ Number of infants delivered } & Single & $111(81.6)$ & $262(95.9)$ & $0.19(0.17,0.82)$ & 0.035 & $0.23(0.97,7.84)$ & 0.243 \\
\hline & $\geq$ Twin & $25(18.4)$ & $11(4.1)$ & 1 & & & \\
\hline \multirow[t]{2}{*}{ Exposed to pesticides during pregnancy } & Yes & 18 (13.2) & $11(4.1)$ & $3.63(1.43,9.63)$ & 0.001 & $3.19(1.31-10.96)$ & 0.001 \\
\hline & No & $118(86.8)$ & $262(95.9)$ & 1 & & 1 & \\
\hline \multirow[t]{2}{*}{ Drank alcohol during the current pregnancy } & Yes & $16(11.2)$ & $13(4.8)$ & $2.67(1.05,7.81)$ & 0.041 & $2.59(0.93,7.25)$ & 0.070 \\
\hline & No & $120(88.8)$ & $260(95.2)$ & 1 & & 1 & \\
\hline \multirow[t]{2}{*}{ Khat chewing during peri-conception } & Yes & $28(21.1)$ & $24(8.8)$ & $2.69(3.51,8.72)$ & 0.002 & $2.40(1.11,5.19)$ & 0.004 \\
\hline & No & $108(79.4)$ & $249(91.2)$ & 1 & & 1 & \\
\hline
\end{tabular}


Although our findings on the detrimental impact of toxic chemical exposure on pregnancy were in line with the studies conducted around the world, a unique aspect of our result was the significant association between khat chewing during the periconceptional period and an increased risk of having congenital malformed infants. Those women who have been chewing khat during their periconceptional period were three times more likely to have malformed infants as compared to their counterparts.

A review of the literature indicated that this is a clear and significant public health issue facing many African countries $[14,21,30]$. For example, in line with our findings, Yemeni pregnant women who chewed khat were 2.02 times more likely to give malformed infants than women who did not chew khat [31]. Similarly, it is also in agreement with other reports that showed substance use during pregnancy was significantly associated with the occurrence of congenital anomalies [32, 33].

In the region where our study was conducted, khat chewing was a common practice by women, even during pregnancy, which could have a damaging effect on fetal development [34]. There are also deep-rooted cultural, social and traditional values for this highly popular but damaging activity. We believe that this may be one of the biggest challenges facing public health officials in Ethiopia, but it is the one that is extremely important to pursue. Folic acid supplementation in early pregnancy may help decrease the risks of congenital anomalies [35], and mothers should be counseled to eat foods fortified with folic acid.

\section{Limitations of the study}

Despite its strengths, this study has several limitations that must be acknowledged. Although our study had a diverse set of participants, an unmatched case-control study design may be affected by many confounding factors and the results may be less reliable, and we were also not able to consider some congenital malformations that could be detected later in life. It would be useful to consider such populations in future studies. Furthermore, the diagnosis of CMs relied only on clinical examinations, and cytogenetic and metabolic analysis were not performed as these procedures were not available in the study hospitals. Hence, the study is likely to miss some congenital anomalies. The authors also acknowledge the limitations associated with the timing and duration of environmental exposure of mothers and selfreported data.

\section{Conclusions}

Although our study has not addressed the issue of preventing $\mathrm{CM}$ during pregnancy, it has identified some of the modifiable risk factors that place pregnant women at high risk of giving malformed infants. Maternal exposure to pesticides during pregnancy and khat chewing during the periconceptional period are two important modifiable risk factors that were significantly associated with congenital anomalies. Hence, due attention should be given to public health interventions targeting khat chewing and maternal exposure to pesticides during pregnancy.

\section{Supplementary information}

Supplementary information accompanies this paper at https://doi.org/10. 1186/s12884-020-2827-0.

Additional file 1. English language version of the consent form and questionnaires which was developed for this study.

\section{Abbreviations}

AOR: Adjusted Odds Ratio; Cl-: Confidence Interval; CMs: Congenital Malformation; COR: Crude Odds Ratio; SPSS: Statistical Package for the Social Sciences

\section{Acknowledgments}

We would like to thank Maddawalabu University for allowing us an opportunity to work on identified thematic areas and financial grants. We are grateful to our study participants, data collectors, and head/directors of hospitals for their great contribution and support. We would also like to acknowledge Maddawalabu University for financial support to carry out this study

Authors' contributions

$A G^{1}, A G^{2}$, and $T$ participated in the design of the study, supervised the data collection, analyzed and interpreted the data. $\mathrm{AG}^{1}$ and $\mathrm{AS}$ drafted and edited the manuscript. All authors read and approved the final manuscript.

\section{Funding}

This study was funded by grant support from Maddawalabu University (protocol No: RCSVP/113/2018) in Ethiopia. The funding university does not have any role in the design of the study, data collection, analysis and interpretation of data, and in writing the manuscript.

Availability of data and materials

All data generated/analyzed during this study are included in this published article. Besides, part of the row datasets will be available from the corresponding author on a reasonable request.

\section{Ethics approval and consent to participate}

Ethical approval was obtained from a research review committee of Madawalabu University. Letters were secured from the Bale zone Health Bureau and respective hospitals. Written informed consent was obtained from each study participant. All information obtained from each study participant was kept confidential throughout the study, and the name of the participant was replaced by code. Withdrawal from the study at any point if they wished was assured.

\section{Consent for publication \\ Not applicable.}

\section{Competing interests}

The authors declare that they have no competing interests.

\section{Author details}

${ }^{1}$ Department of Nursing, College of Health Sciences, Debre Berhan University, Po. Box, 445 Debre Berhan, Ethiopia. ²Department of Surgery, Goba Referral Hospital, Maddawalabu University, Bale Robe, Ethiopia. ${ }^{3}$ Department of Nursing, College of Health Sciences, Ambo University, Ambo, Ethiopia. ${ }^{4}$ School of Public Health and Social Work, Faculty of Health, Queensland University of Technology, Brisbane, Queensland, Australia. 
Received: 21 December 2019 Accepted: 20 February 2020

Published online: 27 February 2020

\section{References}

1. Nhoncanse GC, Germano CM, Avó LR, Melo DG. Maternal and perinatal aspects of birth defects: a case-control study. Revista Paulista de Pediatria. 2014;32(1):24-31.

2. Ahmed W, Dey D, Farid R. Prevalence and pattern of congenital anomalies and its outcome at Chattagram Maa-O-Shishu general hospital. Chattagram Maa-O-Shishu Hospital Med College J. 2017;16(1):22-5.

3. Li Z, Ren A, Zhang L, Guo Z, Li Z. A population-based case-control study of risk factors for neural tube defects in four high-prevalence areas of Shanxi province, China. Paediatr Perinat Epidemiol. 2006;20(1):43-53.

4. Agha MM, Williams JI, Marrett L, To T, Dodds L. Determinants of survival in children with congenital abnormalities: a long-term population-based cohort study. Birth Defects Res A: Clin Mol Teratol. 2006;76(1):46-54.

5. Waller DK, Shaw GM, Rasmussen SA, Hobbs CA, Canfield MA, Siega-Riz AM, et al. Prepregnancy obesity as a risk factor for structural birth defects. Arch Pediatr Adolesc Med. 2007;161(8):745-50.

6. Persson M, Cnattingius S, Villamor E, Söderling J, Pasternak B, Stephansson $\mathrm{O}$, Neovius M. Risk of major congenital malformations in relation to maternal overweight and obesity severity: cohort study of 1.2 million singletons. BMJ. 2017;357:;2563

7. Francine $\mathrm{R}$, Pascale $\mathrm{S}$, Aline $\mathrm{H}$. Congenital anomalies: prevalence and risk factors. Universal J Public Health. 2014;2(2):58-63.

8. Ali WA, Balaha MH, Al Moghannum MS, Hashim I. Risk factors and birth prevalence of birth defects and inborn errors of metabolism in Al Ahsa, Saudi Arabia. Pan Afr Med J. 2011;8(14):1-7. https://doi.org/10.11604/pamj.2011.8.14.483.

9. Lorente C, Cordier S, Goujard J, Aymé S, Bianchi F, Calzolari E, De Walle HE, Knill-Jones R. Tobacco and alcohol use during pregnancy and risk of oral clefts. Occupational exposure and congenital malformation working group. Am J Public Health. 2000;90(3):415.

10. Dolk H, Loane M, Garne E. The prevalence of congenital anomalies in Europe. Adv Exp Med Biol. 2010;686:349-64.

11. World Health Organization. Sixty-Third World Health Assembly. Provisional agenda item 11.7. 2010.

12. Mahela S, Talukdar B. Prevalence of congenital abnormalities on routine ultrasound scan of second and third trimester pregnancy. Int J Reproduction, Contraception, Obstetrics Gynecol. 2016;5(1):183. https://doi. org/10.18203/2320-1770.ijrcog20151621.

13. Taye M, Afework M, Fantaye W, Diro E, Worku A. Factors associated with congenital anomalies in Addis Ababa and the Amhara region, Ethiopia: a case-control study. BMC Pediatr. 2018;18(1):1-11.

14. Ajao $A E$, Adeoye IA. Prevalence, risk factors and outcome of congenital anomalies among neonatal admissions in OGBOMOSO. Nigeria BMC Pediatrics. 2019;19(1):88.

15. Costa CM, Gama SG, Leal MD. Congenital malformations in Rio de Janeiro, Brazil: prevalence and associated factors. Cadernos de saude publica. 2006; 22:2423-31.

16. Sarkar S, Patra C, Dasgupta MK, Nayek K, Karmakar PR. Prevalence of congenital anomalies in neonates and associated risk factors in a tertiary care hospital in eastern India. J Clin Neonatol. 2013;2(3):131.

17. Ameen SK, Alalaf SK, Shabila NP. Pattern of congenital anomalies at birth and their correlations with maternal characteristics in the maternity teaching hospital, Erbil city, Iraq. BMC Pregnancy Childbirth. 2018;18(1):501.

18. Taye M, Afework M, Fantaye W, Diro E, Worku A. Congenital anomalies prevalence in Addis Ababa and the Amhara region, Ethiopia: a descriptive cross-sectional study. BMC Pediatr. 2019;19(1):234.

19. Molla Taye MA, Fantaye W, Diro E, Worku A. Magnitude of birth defects in central and Northwest Ethiopia from 2010-2014: a descriptive retrospective study. PLoS One. 2016;11(10):1-12. https://doi.org/10.1371/journal.pone.0161998.

20. Khattak S, Guiti K, McMartin K, Barrera M, Kennedy D, Koren G. Pregnancy outcome following gestational exposure to organic solvents: a prospective controlled study. Jama. 1999;281(12):1106-9.

21. Mashuda F, Zuechner A, Chalya PL, Kidenya BR, Manyama M. Pattern and factors associated with congenital anomalies among young infants admitted at Bugando medical Centre, Mwanza, Tanzania. BMC Res Notes. 2014;7(1):195.

22. Yard E, Bayleyegn T, Abebe A, Mekonnen A, Murphy M, Caldwell KL, Luce R, Hunt DR, Tesfaye $K$, Abate M, Assefa T. Metals exposures of residents living near the Akaki River in Addis Ababa, Ethiopia: a cross-sectional study. J
Environ Public Health. 2015. 935297. https://www.cdc.gov/nceh/hsb/cwh/ technical ethiopia.htm.

23. Taboo ZA. Prevalence and risk factors for congenital anomalies in Mosul city. Iraqi Academic Scientific Journal. 2012;11(4):458-70.

24. Singh A, Sinha S. Risk factors of congenital malformations in North India: a case-control study. J Postgrad Med Education Res. 2016;50(1):22-7.

25. Bianchi F, Cianciulli D, Pierini A, Costantini AS. Congenital malformations and maternal occupation: a registry based case-control study. Occup Environ Med. 1997:54(4):223-8.

26. Et. Kelsey. StatCalc - Calculating a Sample Size with Epi-Info. 2012. p. 1-17.

27. Sav A, McMillan SS, Kelly F, King MA, Whitty JA, Kendall E, Wheeler AJ. The ideal healthcare: priorities of people with chronic conditions and their carers. BMC Health Serv Res. 2015;15(1):551.

28. Gaspari L, Paris F, Jandel C, Kalfa N, Orsini M, Daurès JP, Sultan C. Prenatal environmental risk factors for genital malformations in a population of 1442 French male newborns: a nested case-control study. Hum Reprod. 2011; 26(11):3155-62.

29. Badawi N, Kurinczuk JJ, Keogh JM, Alessandri LM, O'Sullivan F, Burton PR, Pemberton PJ, Stanley FJ. Intrapartum risk factors for newborn encephalopathy: the Western Australian case-control study. BMJ. 1998; 317(7172):1554-8

30. Eke CB, Uche EO, Chinawa JM, Obi IE, Obu HA, Ibekwe RC. Epidemiology of congenital anomalies of the central nervous system in children in Enugu, Nigeria: a retrospective study. Ann Afr Med. 2016;15(3):126.

31. Abdel-Aleem MA, Al-Aghbari A, Mustafa M, Nasr AA, Assad A. Khat chewing during pregnancy: an insight on an ancient problem impact of chewing khat on maternal and fetal outcome among Yemeni pregnant women. J Gynecol Neonatal Biology. 2015;1(2):28-31.

32. Seyoum G, Adane F. Prevalence and associated factors of birth defects among newborns at referral hospitals in Northwest Ethiopia. Ethiopian $J$ Health Dev. 2018;32(3):1-7.

33. Forray A, Foster D. Substance use in the perinatal period. Current psychiatry reports. 2015;17(11):91

34. Teklie H, Gonfa G, Getachew T, Defar A, Bekele A, Bekele A, Gelibo T, Amenu K, Taddele T, Taye G, Getinet M. Prevalence of Khat chewing and associated factors in Ethiopia: findings from the 2015 national non-communicable diseases STEPS survey. Ethiop J Health Dev. 2017;31(1):320-30.

35. Goh YI, Koren G. Folic acid in pregnancy and fetal outcomes. J Obstet Gynaecol. 2008;28(1):3-13.

\section{Publisher's Note}

Springer Nature remains neutral with regard to jurisdictional claims in published maps and institutional affiliations.

Ready to submit your research? Choose BMC and benefit from

- fast, convenient online submission

- thorough peer review by experienced researchers in your field

- rapid publication on acceptance

- support for research data, including large and complex data types

- gold Open Access which fosters wider collaboration and increased citations

- maximum visibility for your research: over $100 \mathrm{M}$ website views per year

At BMC, research is always in progress.

Learn more biomedcentral.com/submissions 